\title{
Investigation of combustion and gasification mechanically activated coal fuel of various degrees of metamorphism on the 5-MW heat setup
}

\author{
Evgenii Butakov ${ }^{1 *}$, Anatoly Burdukov ${ }^{1}$, and Artem Kuznetsov ${ }^{1}$ \\ ${ }^{1}$ Kutateladze Institute of Thermophysics, SB RAS, Novosibirsk, Russia
}

\begin{abstract}
The technology of mechanochemical activation of combustion and gasification of coals is of unquestionable scientific and technical interest; an increase in chemical activity of coals at their mechanically activated grinding is associated with an increase in the rate of reaction of the coal substance. To study the combustion and gasification process, the reactor model with tangential scroll input of coal-air suspension and cylindrical reaction chamber was used at the 5-MW thermal power plant. The experiments were carried out with coals of G and SS grades of the Kuznetsk deposit. Coal, ground after the boiler's standard mill, is fed by a feeder to the disintegrator; then, it enters the scroll inlet of the reactor burner with transport air. The suspension is ignited by a gas igniting device with the power of $50 \mathrm{~kW}$. In experiments on combustion and gasification of fine coal performed at the temperature in the reaction chamber of 1000 $1300^{\circ} \mathrm{C}$ and air excess $\alpha=0.5-0.7$, the data on concentrations of $\mathrm{CO}$ and $\mathrm{H}_{2}$ were obtained: for coal of grade $\mathrm{G}$, concentration of $\mathrm{H}_{2}$ was $6.3 \%$ and concentration of $\mathrm{CO}$ was $15.3 \%$; for coal of SS grade, concentration of $\mathrm{H}_{2}$ was $9.5 \%$ and concentration of $\mathrm{CO}$ was $15.6 \%$.
\end{abstract}

\section{Introduction}

Russia is the largest coal country, and one third of the world's resources is concentrated in its interior. At the same time, the quality of coal supplied to power plants is constantly deteriorating. At that, burning of low-grade coals at the boiler plants is associated with considerable difficulties, when igniting a coal flame, stabilizing its combustion, and fuel burn-out with simultaneous reduction of ecological parameters of power plants $[1,2]$.

The use of coal in power engineering meets various difficulties, leaving great potential for improving and optimizing the efficiency of combustion technologies. To improve the ignition and stabilization of combustion of the pulverized coal flame, the methods of increasing the grinding fineness, high heating of the air mixture and secondary air, using dust of high concentration, and joint use of fuel oil and coal are usually used. However, these methods have some disadvantages and only partially solve the above-mentioned problems.

*Corresponding author: e butakov@mail.ru 
Recently, plasma technologies of ignition and lighting of a pulverized-coal flame have been actively developed [2]; however, due to relatively low service-life of plasmatrons, the technology is more applicable to the ignition processes at the boiler plants.

The fact of an increase in the chemical activity of coals at their grinding in highly stressed disintegrator mills has been established at the Institute of Thermophysics SB RAS. A number of investigation results related to ignition and combustion of mechanically activated fine coal of different stages of metamorphism have been published [3, 4]. Based on obtained data, a new technology is proposed to replace high-reaction gases and fuel oil by fine coal at the power plants.

\section{Experimental apparatus and procedure}

The experiments were carried out at a pilot setup with the thermal power of $5 \mathrm{MW}$. During the experiment, the temperatures were measured along the entire length of setup, and gas analysis was performed at the outlet of the combustion chamber.

Coal powder with the size of up to $1 \mathrm{~mm}$ or dust after the ball-tube mill (BTM) is fed into the hopper, then through a dispenser, it enters the grinding mill and after grinding it is sent to the funnel, through which it is fed by ejector to the burner with the transport air. The pulverized coal mixture is formed before entering the scroll swirler of the fine-coal burner, where ignition and combustion of the dust-air mixture are subsequently initiated with the help of ignition safety device (ISD). It burns under the lack of air in a muffled combustion chamber, i.e., ignition and partial gasification of coal with the release of volatiles (CO and $\mathrm{H}_{2}$, etc.) occur there. The highly reactive fuel mixture, after partial gasification, enters the afterburner chamber, where it mixes with the secondary air, fed tangentially.

The combustion process can be observed through the inspection windows located along the combustion chamber and afterburner. The temperature control of combustion is performed by eight thermocouples located along the combustion chamber and afterburner. The setup includes the nozzles for sampling the gaseous products of combustion and gasification for gas analysis of their composition. The flow rates of transport, primary, and secondary air are controlled by thermal anemometers and regulated by means of valves and air fans on the ejector.

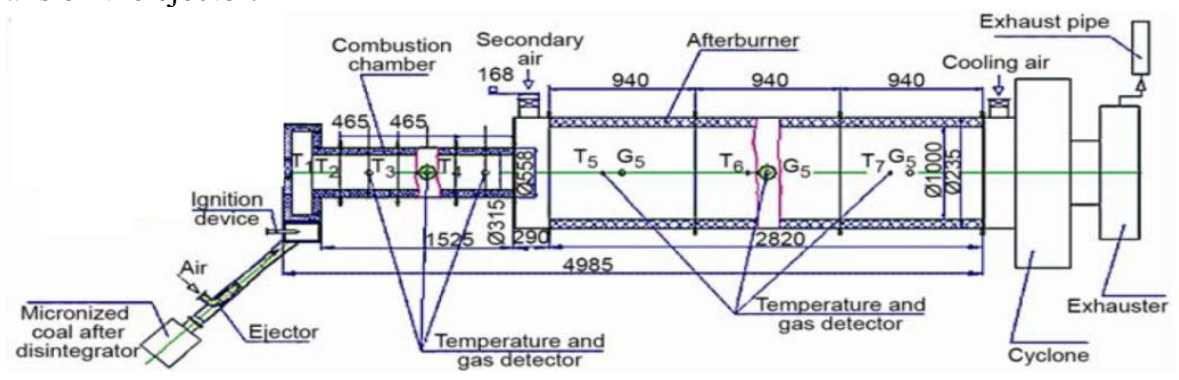

Fig. 1. Experimental setup of up to $5 \mathrm{MW}$.

\section{Results and discussion}

Experiments on ignition, combustion and gasification of Kuznetsk deposit coals (Siberia) of grade $\mathrm{G}$ and $\mathrm{S}$ (gaseous and sintering), crushed at the disintegrator mill with productivity of up to $2 \mathrm{t} / \mathrm{h}$, were carried out. Characteristics of the studied Kuznetsk coals of grade G: moisture $\mathrm{Wrl}-19.0 \%$, ash $\mathrm{A}_{\mathrm{r}}-14.3 \%$, volatile content $-43.5 \%$, sulfur $\mathrm{S}_{\mathrm{dl}}-0.30 \%$, high heat value $\mathrm{Q}_{\mathrm{daf}}-7327 \mathrm{kcal} / \mathrm{kg} ; \mathrm{S}$ : $\mathrm{W}_{\mathrm{rl}}-7.0 \%$, ash $\mathrm{A}_{\mathrm{r}}-13.5 \%$, volatile content $-27.5 \%$, sulfur $\mathrm{S}_{\mathrm{dl}}-0.30 \%$, and high heat value $\mathrm{Q}_{\mathrm{daf}}-8180 \mathrm{kcal} / \mathrm{kg}$. 
Experiments were carried out with air excess $\alpha$ of $0.5-0.7$ and power of the gas ignition device of $50 \mathrm{~kW}$. During the entire experiment, the temperature was measured and gas analysis of the combustion products was carried out. The gas intake tube was located at the end of the combustion chamber, and sampling was performed in the chamber center. During the experiments, the minimum time, required to achieve autothermal combustion, was determined; the time was measured from the beginning of feeding the mechanically activated coal into the combustion chamber prior to disconnecting the lighting-up propanbutane.

The first experiments on studying ignition, stable autothermal combustion and air gasification of coals of two metamorphic stages ( $\mathrm{G}$ and $\mathrm{S}$ ), are presented in this work.

The experiment was as follows: $\sim 100 \mathrm{~s}$ after the beginning of supply of dust-gas coal mixture to the chamber using working ignition gas device (IGD), gas supply was stopped and combustion of coal-dust suspension occurred autothermally; when working with SS coal, autothermal combustion started in $\sim 240 \mathrm{~s}$. After combustion stabilization by the temperature, the main temperature and gas analytical measurements were carried out in the combustion chamber.

Experimental results on ignition and gasification of coals of grade $\mathrm{G}$ and $\mathrm{S}$ are shown in Fig. 2.

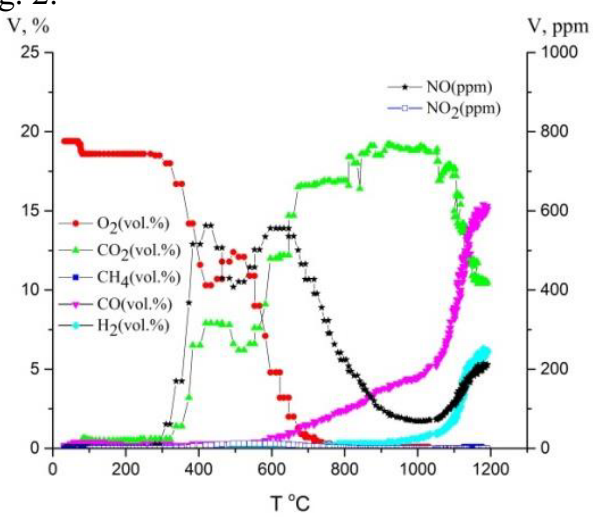

1(a)

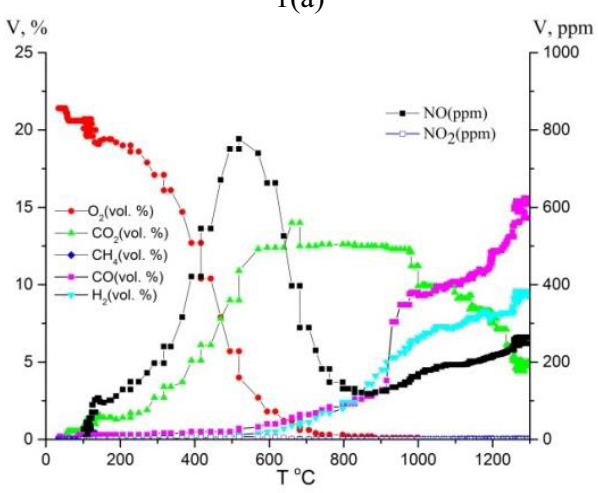

2(a)

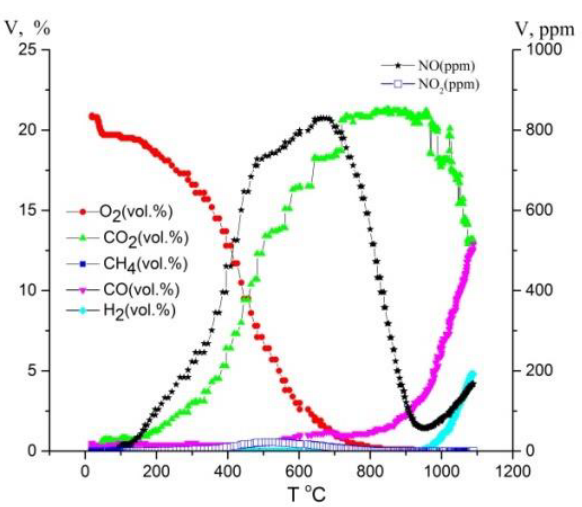

$1(\mathrm{~b})$

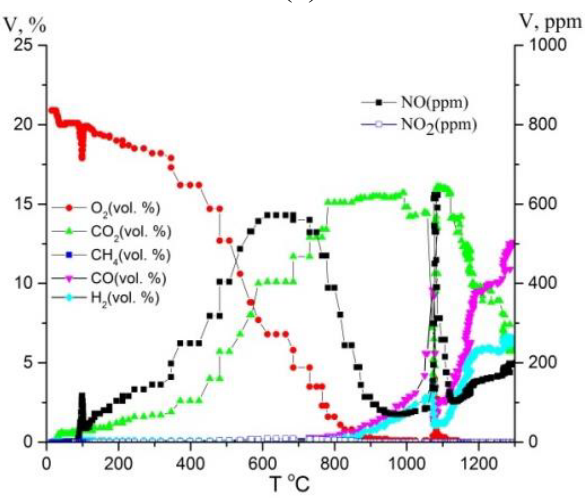

2(b)

Fig. 2. Temperature dependence of concentrations of gas phase components at gasification of mechanically activated coal of grade: $1-\mathrm{G}, 2-\mathrm{S} ; \mathrm{a}-\alpha=0.5 ; \mathrm{b}-\alpha=0.7$.

In all cases, complete burnout of $\mathrm{O}_{2}$ occurs, i.e., along 3 calibers, there is burnout of 50 - 70\% of coal fuel. When $\mathrm{O}_{2}$ reaches $\sim 3 \%$ concentrations of $\mathrm{CO}$ and $\mathrm{H}_{2}$ start increasing. Concentration of $\mathrm{CO}_{2}$ increases and has a maximum at complete burnout of $\mathrm{O} 2$; subsequently it starts decreasing due to reaction of gasification in carbon dioxide $[5,6]$. 
A change in the excess air factor $\alpha$ from 0.7 to 0.5 leads to an increase in maximal concentration of $\mathrm{H}_{2}$ and $\mathrm{CO}$, in the case of coal of grades $\mathrm{H}$, concentration of $\mathrm{H}_{2}$ is $4.8 \%$ $6.3 \%$ and concentration of $\mathrm{CO}$ is $12.9 \%-15.3 \%$; for coal of grade SS, concentration of $\mathrm{H}_{2}$ is $6.6 \%-9.5 \%$ and concentration of $\mathrm{CO}$ is $12.5 \%-15.6 \%$.

\section{Conclusion}

Stable autothermal combustion of the dust suspension of Kuznetsk coals of two grades G and SS has been achieved as a result of their mechanically activated grinding and ignition by a gas burner.

Investigation results on air gasification of these coals confirm the possibility of using the processes of mechanically activated grinding to obtain acceptable values of $\mathrm{H}_{2}$ and $\mathrm{CO}$ concentration.

For obtaining the real high-efficient processes and devices for gasification of fine coal, further studies are needed to optimize the operation parameters: temperature levels, air excess, time of dust suspension stay in the reaction chamber, etc.

Data on ignition and combustion of mechanically activated coals of grade G and SS serve to recommend the technology of microgrinding of these coals for the systems of oilfree firing of the boiler plants.

The work was financially supported by the Russian Foundation for Basic Research (grant - 17-0800445 A)

\section{References}

1. M.Yu. Chernetskiy, A.P. Burdukov, E.B. Butakov, I.S. Anufriev, P.A. Strizhak, Combust., Explosion and Shock Waves 52, 326 (2016)

2. A.P. Burdukov, E.B. Butakov, V.I. Popov, M.Y. Chernetskiy, N.S. Chernetskaya Thermal Science 20, 23 (2016)

3. A.P. Burdukov, V.I. Popov, G.V. Chernova, M.Yu. Chernetskiy, A.A. Dekterev, N.S. Chernetskaya, V.M. Markova, V.N. Churashev, T.S. Yusupov, Thermal Eng. 60, 889 (2013)

4. V.E. Messerle, A.B. Ustimenko, O.A. Lavrichshev, Fuel 164, 172 (2016)

5. N. Couto, V. Silva, E. Monteiro, Appl. Thermal Eng. 78, 185 (2015)

6. R. Mota, G. Krishnamoorthy, O. Dada, S. Benson, Appl. Thermal Eng. 90, 13 (2015) 